\title{
Estudo sobre a epidemiologia da leptospirose na região Sul do Brasil entre os anos 2017 a 2019
}

A leptospirose é uma doença ou infecção naturalmente transmissivel entre os animais vertebrados e o homem. O presente estudo traça um perfil epidemiológico da leptospirose em humanos na região Sul do Brasil, no período de 2017 a 2019 evidenciando a importância que os animais têm como reservatório. Realizou-se um estudo com abordagem quantitativa, derivada de dados do Sistema de Informação de Agravos de Notificação (SINAN) no período de 2017 a 2019 . As variáveis analisadas foram notificações por região do Brasil, taxa anual da região Sul, casos notificados dos estados que integram a região Sul, faixa etária, quantitativo por gênero, zona de residência, local de contaminação e evolução dos casos. Constatou-se que a região Sul é a quarta mais prevalente, sendo a zona urbana mais acometida. A população masculina é a mais afetada pela patologia e a faixa etária mais vulnerável foi dos 40 aos 59 anos. Diante disso ressalta-se a necessidade da importância da vigilância epidemiológica na identificação dos casos, intensificação das ações de controle e orientações adequadas do profissional de saúde quanto ao tratamento, prevenção e promoção da saúde.

Palavras-chave: Leptospira spp; Riscos ambientais; Zoonoses.

\section{Study on the epidemiology of leptospirosis in the South region of Brazil between the years 2017 to 2019}

\begin{abstract}
Leptospirosis is a disease or infection naturally transmissible between vertebrate animals and man. The present study traces an epidemiological profile of leptospirosis in humans in the southern region of Brazil, in the period from 2017 to 2019, showing the importance that animals have as a reservoir. A study was carried out with a quantitative approach, derived from data from the Notifiable Diseases Information System (SINAN) in the period from 2017 to 2019 . The variables analyzed were notifications by region of Brazil, annual rate in the southern region, cases notified from the states that integrate the South region, age group, quantitative by gender, area of residence, place of contamination and evolution of cases. It was found that the southern region is the fourth most prevalent, being the most affected urban area. The male population is the most affected by the pathology and the most vulnerable age group was from 40 to 59 years old. In view of this, the need for the importance of epidemiological surveillance in the identification of cases, intensification of control actions and adequate guidance from health professionals regarding treatment, prevention and health promotion is emphasized.
\end{abstract}

Keywords: Leptospira spp; Environmental risks; Zoonoses.

Topic: Epidemiologia

Reviewed anonymously in the process of blind peer.
Received: 17/10/2020

Approved: 21/01/2021

Bruna Vaz da Silva Gonçalves (iD

Universidade Tuiuti do Paraná, Brasil

http://lattes.cnpq.br/9650391763326837

http://orcid.org/0000-0002-7880-2682

bruvazlain@gmail.com

Isis Regina Barberini (D)

Universidade Tuiuti do Paraná, Brasil

http://lattes.cnpq.br/9482075645403205

http://orcid.org/0000-0003-1939-7194

isisreginaB18@gmail.com

Silvana Krychak Furtado (iD)

Universidade Tuiuti do Paraná, Brasil

http://lattes.cnpq.br/8101364738483981

http://orcid.org/0000-0002-7192-349X

silvana.krychak@utp.br

Referencing this:

GONÇALVES, B. V. S.; BARBERINI, I. R.; FURTADO, S. K.. Estudo sobre a epidemiologia da leptospirose na região Sul do Brasil entre os anos 2017 a 2019. Scire Salutis, v.11, n.1, p.119-126, 2021. DOI: http://doi.org/10.6008/CBPC2236-9600.2021.001.0013 


\section{INTRODUÇÃO}

A leptospirose é uma doença ou infecção naturalmente transmissível entre os animais vertebrados e o homem, de curso agudo a crônico que afeta diversas espécies de animais domésticos e silvestres, além do homem, assumindo considerável importância como problema econômico e de saúde pública (FAINE et al., 2000). O Sistema de Vigilância Epidemiológica da Leptospirose (SNVE-lepto) se caracteriza por ser um sistema passivo e universal, tendo como fonte de informação a notificação espontânea, sendo responsável pelo acompanhamento contínuo da leptospirose, estabelecendo as bases técnicas para elaboração e implementação do programa de controle (BRASIL, 2009). Sua notificação é compulsória no Brasil desde 1993, tanto para o registro de casos suspeitos isolados, como para ocorrência de surtos, conforme o Anexo 1 do Anexo V da Portaria de Consolidação no 4 de 28 de setembro de 2017. Atualmente as notificações são provenientes das unidades de saúde e encaminhadas às vigilâncias epidemiológicas (VE) por meio da ficha de notificação, que contém dados demográficos, antecedentes epidemiológicos e clínicos dos casos. Preconiza-se que essa notificação gere uma investigação para identificar o local provável de infecção (LPI) e possíveis fatores de risco do caso suspeito e esses dados são anotados numa ficha de investigação. $O$ ideal é que essa investigação seja realizada em até sete dias e seja encerrada em no máximo 60 dias para ser considerada oportuna pelo Sistema Nacional de Vigilância Epidemiológica (SNVE) da leptospirose. Todas as informações contidas nas fichas (notificação e investigação) devem ser digitadas no banco de dados do sistema oficial de informação de agravos de notificação (SINAN), geralmente pelo serviço de vigilância municipal. As informações deverão ser repassadas à VE estadual e federal (Coordenação Nacional do Programa de Leptospirose). Uma vez o caso notificado, o material colhido para exame deverá ser enviado ao Laboratório Central de Saúde Pública (LACEN) pela VE e se necessário reencaminhado para o Laboratório de Referência Nacional. O resultado deverá retornar à VE para, então, ser encaminhado ao paciente (BRASIL, 2009). De modo geral, todo sistema de vigilância deve ser simples, contínuo e apresentar, obrigatoriamente, três componentes: coleta e análise de dados e ampla divulgação das informações analisadas. Além disso, todo sistema deve ser avaliado frequentemente e, se necessário, alterado de maneira a garantir o bom desempenho (WALDMAN, 1998). A avaliação contínua do SNVE, baseada em critérios de utilidade, oportunidade e qualidade representam insumos essenciais para o planejamento, monitoramento, execução e avaliação das ações de saúde, promovendo sua melhoria gerando como resposta ações que propiciem aprimoramento da compreensão do agravo (ROMERO et al., 2007).

\section{REVISÃO TEÓRICA}

A leptospirose é uma doença infecciosa causada por bactérias do gênero Leptospira e é uma zoonose de ampla distribuição, com significativo impacto social, econômico e sanitário. Esta doença acomete o ser humano e praticamente todos os animais domésticos e alguns animais selvagens, entre os quais se destacam os carnívoros, roedores, primatas e marsupiais, que podem se tornar portadores e contribuírem para a disseminação do microrganismo na natureza. A leptospirose foi descrita pela primeira vez em 1880, no Cairo, 
por Larrey; no entanto foi em 1886 que Weil descreveu minuciosamente, quatro casos clínicos em humanos (BRASIL, 2009). A leptospirose distribui-se pelo globo terrestre, mas sua ocorrência é maior em países de clima tropical e subtropical devido à maior sobrevida das leptospiras em ambientes quentes e úmidos. A doença é sazonal, com picos epidêmicos no verão ou outono em regiões de clima temperado, ou durante as estações de chuva nas regiões quentes. Em alguns países como o Brasil a infecção ocorre sob a forma de surtos em seres humanos e animais associados a períodos de alta pluviosidade, presença de roedores e mamíferos silvestres e domésticos bem como águas represadas com altas concentrações de animais (PLANK et al., 2000; BRASIL, 2009). A leptospirose apresenta-se usualmente sob a forma endêmica e sua morbidade é bastante alta em todos os países em que tem sido estudada, porém, os sorovares variam de região para região. A manutenção do agente na natureza está assegurada pelos portadores domésticos e silvestres (CORREA et al., 1991). Os fatores climáticos, incluindo índice pluviométrico, temperatura e umidade relativa do ar, influenciam de maneira decisiva na ocorrência da doença (BRASIL, 1999). O mecanismo molecular da patogênese da leptospirose ainda não é claro (EVANGELISTA et al., 2010). As leptospiras patogênicas podem penetrar por via cutânea ou por mucosas, se disseminando rapidamente para outros tecidos após a infecção, através da via hematógena assim como da sua capacidade de translocação celular (BAROCCHI et al., 2002). A infecção causa uma prolongada leptospiremia até que o hospedeiro possa montar uma resposta imune efetiva, que ocorre uma ou duas semanas após a exposição (FAINE et al., 2000). Quando a infecção é instalada, pode ocorrer a evolução para uma doença aguda, o desenvolvimento de imunidade protetora e eliminação do agente ou o desenvolvimento do estado de portador crônico. Neste último caso, estudos indicam que o lúmen dos túbulos renais, local onde a concentração de anticorpos é baixa, é um local de colonização ideal para as leptospiras, sendo provavelmente uma forma de escape do sistema imune (FAINE et al., 2000; ATHANAZIO et al., 2008). Os rins colonizados por leptospiras apresentam nefrite túbulointersticial, focos inflamatórios, necrose tubular e hemorragias. As leptospiras são encontradas em grande número nos túbulos contorcidos proximais, glomérulos e interstício (NALLY et al., 2004). No fígado, as leptospiras causa dano hepatocelular, com perda da arquitetura tecidual, focos de necrose hepatocitária, focos de inflamação, presença de células de Kupffer aumentadas e eventualmente presença de células apoptóticas (NALLY et al., 2004). O dano pulmonar principal na leptospirose ocorre devido às intensas hemorragias intra-alveolares, levando à insuficiência respiratória. Raras leptospiras são visualizadas nos pulmões, o que sugere um mecanismo diferente de patogenia que não a ação direta do microrganismo, assim como a presença do agente em tecidos renais e hepáticos não estão relacionados com lesão (CRODA et al., 2010). O início dos sintomas da doença está relacionado com o surgimento dos anticorpos e a eliminação das leptospiras ocorrem através da opsonização e lise mediada pelos mesmos. A resposta humoral é específica para o sorovar infectante. O dano vascular endotelial é a principal lesão na leptospirose grave e causa extravasamento capilar, hemorragias e vasculites (LEVETT, 2001). O diagnóstico da leptospirose é confirmado por diferentes métodos laboratoriais baseados na detecção de anticorpos, na detecção direta ou indireta do agente ou do material genético da bactéria na urina ou nos tecidos (ROSA, 1980; FAINE et al., 2000). O isolamento de leptospiras permite o diagnóstico definitivo da leptospirose e a identificação do sorovar 
infectante, dado este importante para orientar ações destinadas ao controle e profilaxia da doença (VASCONCELLOS, 2004; FAINE et al., 2000). Os animais acometidos pela infecção da leptospirose podem ser passíveis a duas modalidades: doentes portadores convalescentes e os portadores assintomáticos. A infecção por Leptospira spp ocorre através das mucosas ou de lesões de pele, seguindo-se da sua multiplicação no sangue e praticamente em todos os órgãos e tecidos. Nos animais que conseguem sobreviver à fase aguda da leptospirose, os microrganismos alcançam o sistema renal e passam a ser excretados pela urina por períodos de tempo variados, caracterizando-os como portador convalescentes. A leptospirose canina representa um sério problema sanitário, não só pela gravidade da doença, mas também pelo potencial de contágio ao homem, devido à proximidade estabelecida entre os seres humanos e os cães. Estudos sobre a presença de leptospiras em animais silvestres e sinantrópicos foram realizados em roedores, carnívoros, e vários outros animais, os quais podem atuar como fonte de infecção e potenciais disseminadores dos diferentes sorovares de Leptospira spp. Neste contexto, o objetivo deste trabalho é contribuir com dados epidemiológicos dos casos de leptospirose na Região Sul, analisando-se os dados de 2017 a 2019, disponibilizados pelo Sistema de informação de Agravos de Notificação (SINAN), a fim de fornecer subsídios para o planejamento e avaliação das ações de saúde em leptospirose na região.

\section{METODOLOGIA}

Realizou-se um estudo com abordagem quantitativa, derivada de dados do Sistema de Informação de Agravos de Notificação (SINAN) no período de 2017 a 2019. As variáveis analisadas foram notificações por região do Brasil, taxa anual da região Sul, casos notificados dos estados que integram a região Sul, faixa etária, quantitativo por gênero, zona de residência, local de contaminação e evolução dos casos. A análise dos dados foi realizada por meio do software Excel (Microsoft ${ }^{\circledR}$ ). A prevalência foi analisada através de cálculos realizados no programa Tabwin por meio da fórmula: número de casos notificados/população da variável $\mathrm{x}$ 100.000 (a população estimada dos anos 2017 a 2019 foi retirada do Instituto Brasileiro de Geografia e Estatística - IBGE).

\section{RESULTADOS}

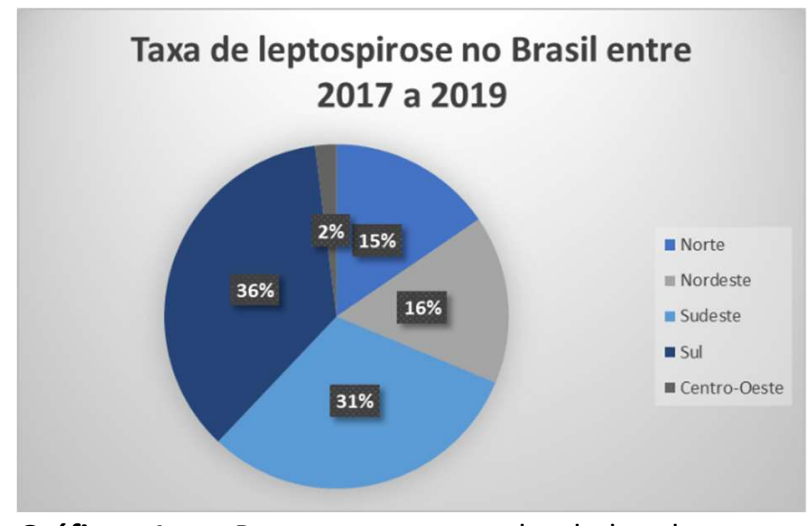

Gráfico 1: Porcentagem arredondada dos casos notificados de leptospirose no Brasil entre os anos de 2017 a 2019 entre as regiões do Brasil.

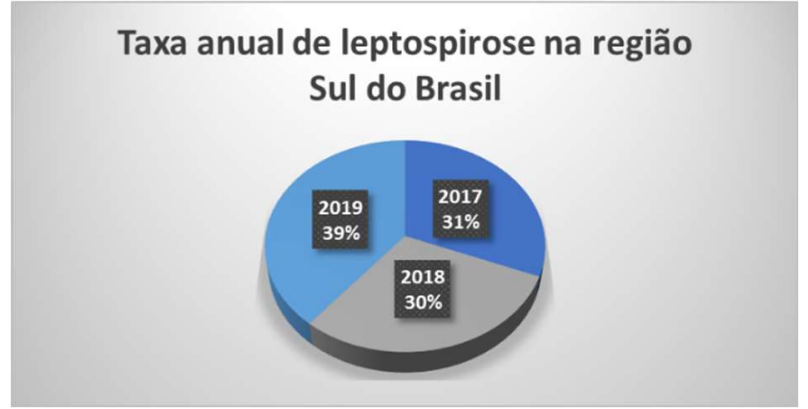

Gráfico 2: Porcentagem anual dos casos notificados de leptospirose na região entre os anos de 2017 a 2019. 
Quadro 1: Prevalência de infectados em ordem decrescente por região no Brasil entre os anos de 2017 a 2019.

\begin{tabular}{|l|l|}
\hline Região & Taxa de infectados \\
\hline Sul & $3,8 / 100.000$ habitantes \\
\hline Norte & $2,6 / 100.000$ habitantes \\
\hline Sudeste & $1,1 / 100.000$ habitantes \\
\hline Nordeste & $0,8 / 100.000$ habitantes \\
\hline Centro-Oeste & $0,3 / 100.000$ habitantes \\
\hline
\end{tabular}

Quadro 2: Prevalência de infectados em ordem decrescente por estado integrante da região Sul entre os anos de 2017 a 2019.

\begin{tabular}{|l|l|}
\hline Estado & Taxa de infectados \\
\hline Rio Grande do Sul & $4,7 / 100.000$ habitantes \\
\hline Santa Catarina & $3,8 / 100.000$ habitantes \\
\hline Paraná & $2,8 / 100.000$ habitantes \\
\hline
\end{tabular}

Quadro 3: Perfil dos casos notificados de leptospirose na região Sul entre os anos 2017 a 2019.

\begin{tabular}{|c|c|c|}
\hline Característica & Número de casos & $\%$ \\
\hline \multicolumn{3}{|l|}{ Sexo } \\
\hline Feminino & 463 & 13,5 \\
\hline Masculino & 2.966 & 86,4 \\
\hline \multicolumn{3}{|l|}{ Raça } \\
\hline Branca & 2.825 & 82,3 \\
\hline Preta & 122 & 3,5 \\
\hline Parda & 318 & 9,2 \\
\hline Amarela & 16 & 0,4 \\
\hline Indígena & 6 & 0,17 \\
\hline Ign/Branco & 142 & 4,1 \\
\hline \multicolumn{3}{|l|}{ Faixa etária (anos) } \\
\hline$<1$ & 22 & 0,6 \\
\hline $1-4$ & 7 & 0,2 \\
\hline $5-9$ & 33 & 0,9 \\
\hline $10-14$ & 117 & 3,4 \\
\hline $15-19$ & 262 & 7,6 \\
\hline $20-39$ & 1.238 & 36,1 \\
\hline $40-59$ & 1.317 & 38,4 \\
\hline $60-79$ & 419 & 12,2 \\
\hline$\geq 80$ & 14 & 0,4 \\
\hline \multicolumn{3}{|l|}{ Zona de Residência } \\
\hline Urbana & 2.297 & 66,9 \\
\hline Rural & 996 & 29 \\
\hline Periurbana & 34 & 0,9 \\
\hline Ign/Branco & 102 & 2,9 \\
\hline \multicolumn{3}{|l|}{ Local provável de infecção } \\
\hline Domiciliar & 1.311 & 38,2 \\
\hline Trabalho & 840 & 24,4 \\
\hline Lazer & 374 & 10,9 \\
\hline Outro & 161 & 4,6 \\
\hline Ign/Branco & 743 & 21,6 \\
\hline \multicolumn{3}{|l|}{ Evolução dos casos } \\
\hline Cura & 3.085 & 89,9 \\
\hline Óbito pelo agravo notificado & 144 & 4,1 \\
\hline Óbito por outra causa & 22 & 0,6 \\
\hline Ign/Branco & 178 & 5,1 \\
\hline
\end{tabular}

\section{DISCUSSÃO}

No período estudado, o Brasil registrou 9.537 casos de leptospirose, em que 35,9\% (3.429/9.537) destes corresponderam aos estados da região Sul do Brasil, conforme observado no gráfico 1. Os dados coletados permitiram estabelecer uma prevalência de infectados por região no Brasil (Quadro 1). Sendo que a região Sul apresenta uma taxa de 3,8 infectados a cada 100.000 habitantes, se caracteriza como a região 
mais prevalente do Brasil. O número de casos notificados da região Sul ficou em 2017 com 31\% (1.066/3.429), seguido por 2018 com 30\% (1.023/3.429) e 2019 perfazendo 39\% (1.340/3.429). O ideal é a diminuição anual dos casos, porém o que se observa entre 2017 e 2018 é uma invariabilidade desses casos e o aumento em 2019 demonstrando a importância do estudo desta patologia para saúde pública (Gráfico 2). Considerandose os três estados que compõe a região Sul do Brasil os dados permitem avaliar uma taxa de infectados variando entre 2,8 até 4,7 por 100.000 habitantes (Quadro 2). Em relação ao perfil das pessoas acometidas pela doença observou-se através do quadro 3 que em relação ao sexo, evidenciou-se no período supracitado uma maior notificação de leptospirose no sexo masculino com 86,4\% (2.966/3.429) contra 13,5\% (463/3.429) dos casos em mulheres. Alguns autores como Paploski et al. (2013), Busato et al. (2017) e Souza et al. (2011) atribuem a maior incidência no sexo masculino a um maior risco de exposição ao agente em função de suas atividades laborais, porém não existe diferença de susceptibilidade quando ambos os sexos estão expostos às mesmas fontes de contágio. Ainda há a hipótese de que a leptospirose no sexo feminino cursa com uma forma mais branda da doença, fazendo com que os sistemas de vigilância, que são enviesados para casos mais severos, detectem menos casos em indivíduos do sexo feminino, diminuindo a incidência de manifestações neste sexo. O perfil étnico dos casos notificados revelou os brancos como grupo mais afetado, com 82,3\% (2.825/3.429) dos casos. No tocante à faixa etária, a ocorrência entre pessoas com 40 a 59 anos se fez em 38,4\% (1.317/3.429) e de 20 a 39 anos se fez em 36,1\% (1.238/3.429). Com relação à faixa etária mais acometida, possivelmente determinadas ações de risco são executadas com maior frequência por indivíduos em idade laboral, associada à exposição ocupacional, já que estes podem desempenhar funções que facilitam o contato com as fontes de infecção. Já as crianças menores de quatro anos e idosos, tem contato mais limitado com solo e água contaminada (PAPLOSKI et al., 2013; BUSATO et al., 2017; SOUZA et al., 2011). Quanto à zona de residência observou-se registro de 66,9\% (2.297 /3.429) dos casos em região urbana e 29\% (996/3.429) em região rural. A ocorrência de leptospirose está estreitamente vinculada aos fatores ambientais, que podem dar lugar a um foco de infecção, cuja amplitude está na dependência de condições favoráveis. Podem permanecer viáveis em água limpa por até 152 dias, mas não toleram alta salinidade, dessecação, pH ácido e a competição bacteriana em meios muito contaminados. Sem dúvida a água das chuvas é ideal para a sua sobrevivência. Já a predominância da leptospirose em área urbana pode estar relacionada a baixos níveis socioeconômicos, com moradias precárias, proximidade de rios e córregos e alta infestação de roedores. Na zona urbana, principalmente em grandes cidades, durante a época das chuvas, as inundações constituem-se no principal fator de risco para a ocorrência de surtos epidêmicos de leptospirose humana (GENOVEZ, 2009; PELISSARI et al., 2011). Na zona rural, as características da ambiência e a presença de animais silvestres assumem grande importância na transmissão da leptospirose, indicando que a exposição ocupacional de agricultores é um fator de risco bem descrito. Localidades com más condições de saneamento básico são principalmente acometidas de surtos devido à presença de esgoto a céu aberto e lixões, proximidade com córregos, os quais propiciam o contato direto com as águas contaminadas com urina de roedores sinantrópicos (ratos e camundongos) e cães errantes (BUSATO et al., 2017; SOUZA et al., 2011). Avaliando o local de contaminação, o domiciliar contém o maior número de 
notificações com 38,2\% (1.311/3.429) dos casos acometidos no Sul, já o local de trabalho perfaz 24,4\% (840/3.429), sendo que $21,6 \%$ das notificações (743/3.429) não consta o local de contaminação (Ign/Branco). O que dificulta um estudo epidemiológico aprofundado para a interrupção da transmissão. Quanto a evolução da doença, os casos de cura se fez em 89,9\% (3.085/3.429) e óbito por agravo notificado ficando em 4,1\% (144/3.429 dos casos. As notificações quanto a evolução dos casos demonstrou um bom manejo da doença, apesar de ainda estar aquém do ideal. Trata-se de uma doença de baixa letalidade, mas que causa enormes gastos na saúde pública com internações e medicamentos, tendo em vista que atinge pessoas de menor renda devido às precárias condições de moradia e saneamento (SOUZA et al., 2011). Estudos encontrados pela literatura afirmam que o risco de transmissão das leptospiras patogênicas, ainda não pode ser mensurado de forma precisa, devido à complexidade que se observa para o diagnóstico laboratorial específico nas várias regiões brasileiras. Fatores como a falta de investimentos em saúde, em infraestrutura de saneamento e em tecnologia para diagnósticos sempre está à margem das reais necessidades de acesso à população o que dificulta o controle e a prevenção da leptospirose no Brasil.

\section{CONCLUSÕES}

Através do presente estudo atentou-se que a interrupção da transmissão não é tarefa simples, pois seu ciclo é complexo, com forte influência das condições ambientais que favorecem o crescimento bacteriano e sua propagação. O reconhecimento eficaz, tratamento e controle da doença tornam necessário o amplo domínio da epidemiologia e dos fatores de risco sociais e ambientais. São necessárias, portanto, abrangentes e eficientes obras de saneamento básico, educação em saúde, fiscalização sanitária e controle de pestes. Diante disso, ressalta-se a necessidade da importância da vigilância epidemiológica na identificação dos casos, intensificação das ações de controle e orientações adequadas do profissional de saúde quanto ao tratamento, prevenção e promoção da saúde. Além disso, a vigilância dos casos facilita o reconhecimento das intervenções necessárias, a reorganização dos serviços de saúde e o planejamento de ações de saúde voltadas ao controle do agravo.

\section{REFERÊNCIAS}

ATHANAZIO, D. A.; SILVA, E. F.; SANTO, C. S.; ROCHA, G. M.; VANNIERSANTOS, M. A.; MCBRIDE, A. J.; KO, A. I.; REIS, M. G.. Rattus norvegicus as a model for persistent renal colonization by pathogenic Leptospira interrogans. Acta Trop., v.105, n.2, p.176-180, 2008.

BAROCCHI, M. A.; KO, A. I.; REIS, M. G.; MCDONALD, K. L.; RILEY, L. W.. Rapid translocation of polarized MDCK cell monolayers by Leptospira interrogans, an invasive but nonintracellular pathogen. Infect. Immun., v.70, n.12, p.6926-6932, 2002.

BRASIL. Ministério da Saúde. Manual de leptospirose. 4 ed. Brasília: Ministério da Saúde, 1999.

BRASIL. Ministério da Saúde. Departamento de Vigilância Epidemiológica. Guia de Vigilância Epidemiológica. 7 ed. Brasília: Ministério da Saúde, 2009.
BUSATO, M. A.; SCHABAT, F. M.; LUNKES, E. F.; LUTINSKI, J. A.; CORRALLO, V. S.. Incidência de leptospirose e fatores associados no município de Chapecó, Santa Catarina, Brasil. Revista de Epidemiologia e Controle de Infecção, v.7, n.4, p.221-226, 2017.

CRODA, J.; NETO, A. N.; BRASIL, R. A.; PAGLIARI, C.; NICODEMO, A. C.; DUARTE, M. I.. Leptospirosis pulmonary haemorrhage syndrome is associated with linear deposition of immunoglobulin and complement on the alveolar surface. Clin. Microbiol. Infect., v.16, p.593-9, 2010.

CORREA, W. M.; CORREA, C. N. M.. Enfermidades infecciosas dos mamíferos domésticos. São Paulo: Varella, 1991. 
EVANGELISTA, K. V.; COBURN, J.. Leptospira as an emerging pathogen: a review of its biology, pathogenesis and host immune responses. Future Microbiol., v.5, p.1413-25. 2010.

FAINE, S.; ADLER, B.; BOLIN, C.; PEROLAT, P.. Leptospira and Leptospirosis. 2 ed. Melbourne: MedSci, 2000.

GENOVEZ, M. E.. Leptospirose: uma doença de ocorrência além da época das chuvas. Biológico, v.71, n.1, p.1-3, 2009.

LEVETT, P. N.. Leptospirosis. Clin. Microbiol. Rev., v.14, n.2, p.296-326, 2001.

NALLY, J. E.; CHANTRANUWAT, C.; WU, X. Y.; FISHBEIN, M. C.; PEREIRA, M. M.; SILVA, J. J.; BLANCO, D. R.; LOVETT, M. A.. Alveolar septal deposition of immunoglobulin and complement parallels pulmonary hemorrhage in a guinea pig model of severe pulmonary leptospirosis. Am. J. Pathol., v.164, n.3, p.1115-27, 2004.

PAPLOSKI, I. A. D.. História natural da leptospirose urbana: influência do sexo e da idade no risco de infecção, progressão clínica da doença e óbito. Tese (Doutorado) Centro de Pesquisas Gonçalo Moniz, Salvador, 2013.

PELISSARI, D. M.; MAIA-ELKHOURY, A. N. S.; ARSKY, M. D. L. N. S.; NUNES, M. L.. Revisão sistemática dos fatores associados à leptospirose no Brasil, 2000-2009. Epidemiologia e Serviços de Saúde, v.20, n.4, p.565-574, 2011.
PLANK, R.; DEAN, D.. Overview of the epidemiology, microbiology, and pathogenesis of Leptospira spp. Inhumans. Microbes and Infection, v.2, p.1265-1276, 2000.

ROMERO, D. E.; CUNHA, C. B.. Avaliação da qualidade das variáveis epidemiológicas e demográficas do sistema de informações sobre nascidos vivos, 2002. Cadernos de Saúde Pública, v.23, n.3, p.701-714, 2007.

ROSA, C. A. S.; SULZER, C. R.; GIORGI, W.; SILVA, A. S.; YANAGUITA, R. M.; LOBÃO, A. O.. Leptospirosis in wildlife in Brazil: isolation of anew serotype in the Pyrogenes group. American Journal of Zoonosis, v.7, p.40-43, 1980.

SOUZA, V. M. M. D.; ARSKY, M. D. L. N. S.; CASTRO, A. P. B. D.; ARAUJO, W. N.. Danos potenciais de vida perdidos e custos hospitalares da leptospirose no Brasil. Revista de Saúde Pública, v.45, p.1001-1008, 2011.

VASCONCELLOS, S.. Laboratory diagnosis of leptospirosis in animals. In: SIMPOSIO INTERNACIONAL SOBRE LEPOSPIRA Y LEPTOSPIROSIS EN LAS AMÉRICAS; DIVISÕES EDUCACIÓN CONTINUA DE LA UNIVERSIDADE NACIONAL AUTÔNOMA DE MÉXICO. Anais. Ciudad del México, 2004. p.70-76.

WALDMAN, E. A.. Usos da vigilância e da monitorização em saúde pública. IESUS, v.7, n.3, p.7-26, 1998.

A CBPC - Companhia Brasileira de Produção Científica (CNPJ: 11.221.422/0001-03) detém os direitos materiais desta publicação. Os direitos referem-se à publicação do trabalho em qualquer parte do mundo, incluindo os direitos às renovações, expansões e disseminações da contribuição, bem como outros direitos subsidiários. Todos os trabalhos publicados eletronicamente poderão posteriormente ser publicados em coletâneas impressas sob coordenação da Sustenere Publishing, da Companhia Brasileira de Produção Científica e seus parceiros autorizados. Os (as) autores (as) preservam os direitos autorais, mas não têm permissão para a publicação da contribuição em outro meio, impresso ou digital, em português ou em tradução. 